\title{
Article
}

\section{Application of hot melt extrusion for improving bioavailability of artemisinin a thermolabile drug}

Kulkarni, C., Kelly, A. L., Gough, T., Jadhav, V., Singh, Kamalinder and Paradkar, A.

Available at http://clok.uclan.ac.uk/20812/

Kulkarni, C., Kelly, A. L., Gough, T., Jadhav, V., Singh, Kamalinder ORCID: 00000001-7325-0711 and Paradkar, A. (2017) Application of hot melt extrusion for improving bioavailability of artemisinin a thermolabile drug. Drug

Development and Industrial Pharmacy . pp. 1-9. ISSN 0363-9045

It is advisable to refer to the publisher's version if you intend to cite from the work. http://dx.doi.org/10.1080/03639045.2017.1386200

For more information about UCLan's research in this area go to http://www.uclan.ac.uk/researchgroups/ and search for <name of research Group>.

For information about Research generally at UCLan please go to http://www.uclan.ac.uk/research/

All outputs in CLoK are protected by Intellectual Property Rights law, including Copyright law. Copyright, IPR and Moral Rights for the works on this site are retained by the individual authors and/or other copyright owners. Terms and conditions for use of this material are defined in the policies page.

\section{CLoK}

Central Lancashire online Knowledge www.clok.uclan.ac.uk

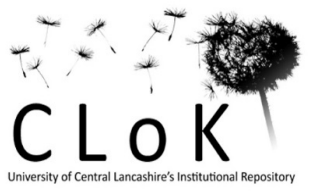




\section{Application of hot melt extrusion for improving bioavailability of artemisinin a thermolabile drug}

C. Kulkarni ${ }^{1}$, A. L. Kelly1, T. Gough ${ }^{1}$, V. Jadhav2, K. K Singh ${ }^{3}$, A. Paradkar $^{1 *}$

1Centre of Pharmaceutical Engineering Science, University of Bradford, Bradford, UK, $B D 71 D P$

2C U Shah College of Pharmacy, Shreemati Nathibai Damodar Thackersey (SNDT) Women's University, Mumbai, India

3School of Pharmacy and Biomedical Sciences, University of Central Lancashire, Preston, Lancashire, UK

* Corresponding Author:

Professor Anant Paradkar

Centre for Pharmaceutical Engineering Science, University of Bradford, Richmond Road, BD7 1DP, UK

Email: A.Paradkar1@bradford.ac.uk

Tel: +44127423390 


\title{
Application of hot melt extrusion for improving bioavailability of thermolabile API
}

\begin{abstract}
Abstract: Hot melt extrusion has been used to produce a solid dispersion of the thermolabile drug artemisinin. Formulation and process conditions were optimised prior to evaluation of dissolution and biopharmaceutical performance. Soluplus ${ }^{\circledR}$, a low Tg amphiphilic polymer especially designed for solid dispersions enabled melt extrusion at $110^{\circ} \mathrm{C}$ although some drug-polymer incompatibility was observed. Addition of 5\% citric acid as a $\mathrm{pH}$ modifier was found to suppress the degradation. The area under plasma concentration time curve (AUC ${ }_{0-24 h r}$ ) and peak plasma concentration $\left(\mathrm{C}_{\max }\right)$ were four times higher for the modified solid dispersion compared to that of pure artemisinin.
\end{abstract}

Key words: Extrusion, thermolabile drug, artemisinin, Soluplus ${ }^{\circledR}$, compatibility, bioavailability.

\section{Introduction}

Hot melt extrusion (HME) has been widely used in the pharmaceutical industry to prepare solid dispersions to improve bioavailability of poorly water soluble drugs ${ }^{1,2}$. During processing of solid dispersions by HME, the hydrophobic drug is processed with a thermoplastic polymer in the molten state to obtain a stabilised amorphous form. In HME the selection of a suitable polymer plays a vital role in successful formulation, in addition to the choice of suitable extrusion conditions. Typically the extrusion process should be carried out at least $20-40^{\circ} \mathrm{C}$ above the glass transition temperature (Tg) of the polymer. The suitability of a polymer for HME can be determined by its thermal and rheological properties ${ }^{3}$.

Exposure of material to high temperature is one of the major concerns during HME, as this may adversely affect stability of the $\operatorname{drug}^{4}$ or polymer ${ }^{5}$. There are also increased 
chances of interaction between drug and polymer at high temperature and shear during HME. This degradation or interaction may result in generation of impurities ${ }^{5,6}$, unexpected change in rheology of the melt ${ }^{7}$ or discolouration of the product ${ }^{5}$. Processing at high temperature is not suitable for some Active Pharmaceutical Ingredients (APIs) due to thermal decomposition which may be followed by loss of pharmacological activity ${ }^{8}$ and therefore prevention of degradation is a major challenge during extrusion processing. These issues have restricted pharmaceutical applications of HME, yet to date relatively few reports are available on these degradation issues. In such cases, the addition of plasticizer is one of the approaches used to lower the Tg and melt viscosity, allowing extrusion to be performed at lower temperatures ${ }^{9,10}$. Lowering the processing temperature can reduce degradation of the drug and facilitate drug stability in pharmaceutical formulations ${ }^{11}$ however, the added plasticiser contributes significantly to the bulk of the formulation and can adversely affect the mechanical properties, drug release rate and stability of the final product ${ }^{12}$. Therefore, alternative approaches are required to facilitate the processing of thermally sensitive drugs. The objective of this work is to investigate and address challenges in the application of HME for processing solid dispersions containing the thermolabile drug, artemisinin using a recently introduced low Tg polymer.

Artemisinin, a keystone of malaria treatment, is effective against Plasmodium falciparum infection and cerebral malaria ${ }^{13}$. Artemisinin has low bioavailability and poor water solubility; its molecular structure is displayed in Fig. 1. Due to its thermolabile nature, artemisinin poses significant processing challenges to forming solid dispersions ${ }^{14}$. Several studies have described attempts to improve the solubility of artemisinin, such as micronisation using supercritical fluid technology, solid dispersions prepared using a solvent evaporation method ${ }^{15}$ and complexation ${ }^{16,17}$. However, these 
methods are complex, difficult to scale-up and yielded relatively poor improvements in drug release properties. Here, an amphiphilic graft copolymer, Soluplus ${ }^{\circledR}$ (polyvinyl caprolactum polyvinyl acetate polyethylene glycol) was used to form solid dispersions with artemisinin using HME, as it has the ability to enhance the solubility of poorly water soluble drugs and is suitable for melt extrusion below $120^{\circ} \mathrm{C}$, without the need for incorporation of additional plasticiser ${ }^{18,19}$.

During preformulation the polymeric matrix is selected on the basis of drug-polymer miscibility, glass transition temperature and rheology of the mixture in the molten state. Screening at the preformulation level generally involves thermal analysis, rheological testing, miscibility predictions using the Florey-Huggins equation and hot stage microscopy ${ }^{20,21}$. Oscillatory rheometry can also be used to study flow behaviour and stability of the drug polymer mixture under oscillatory shear. This enables the structural dynamics of complex fluids to be investigated at precisely controlled temperature and deformation. Here, oscillatory rheometry has been used as a screening tool to optimise processing temperatures and drug loading and to study the effect of additives under shear. Particular challenges included processing, stability and biopharmaceutical performance, all of which are described in detail.

\section{Materials and methods}

Artemisinin was supplied from Cipla Pharmaceuticals Ltd (ART25062007). Soluplus ${ }^{\circledR}$ was kindly provided by BASF Chemicals. All other chemicals and solvents used were of analytical grade.

\subsection{Thermal analysis}

The onset of thermal degradation of artemisinin and Soluplus ${ }^{\circledR}$ was analysed using a Q5000 Thermo Gravimetric Analyser (TGA) (TA Instruments, UK) equipped with a RSC90 cooling unit. Each aluminium pan was calibrated for mass before loading. 
Approximately $5 \mathrm{mg}$ of sample was loaded into each aluminium pan and heated at a rate of $10^{\circ} \mathrm{C} / \mathrm{min}$ over the temperature range 25 to $200^{\circ} \mathrm{C}$. An inert atmosphere was maintained by purging with nitrogen gas at a flow rate of $30 \mathrm{ml} / \mathrm{min}$. Differential Scanning Calorimetry (DSC) studies were carried out using a Q2000 DSC (TA Instruments, UK) equipped with an RSC90 cooling unit. Indium standards were used to calibrate the DSC temperature and enthalpy scales. For each test approximately $4 \mathrm{mg}$ of sample was hermetically sealed in an aluminium pan and a similar empty pan used as a reference. The pans were heated at a constant rate of $10^{\circ} \mathrm{C} / \mathrm{min}$ over a temperature range of 25 to $170^{\circ} \mathrm{C}$ for artemisinin and from 25 to $200^{\circ} \mathrm{C}$ for Soluplus ${ }^{\circledR}$. An inert atmosphere was maintained by purging nitrogen at a flow rate of $50 \mathrm{ml} / \mathrm{min}$.

\subsection{Oscillatory Rheometry}

The rheological behaviour of artemisinin, Soluplus ${ }^{\circledR}$ and physical mixtures in different ratios was studied using an MCR 501 rotational rheometer (Anton Paar, Austria), equipped with a temperature controlled chamber. Physical mixtures of artemisinin and Soluplus ${ }^{\circledR}$ were prepared in 1:1, $1: 3$ and 1:5 ratios (w/w) (50, 25 and 16.7\% (w/w) respectively) by blending in a Turbula mixer for 10 minutes. Parallel plates of diameter $25 \mathrm{~mm}$ were used for rheological characterisation with the distance between the plates set to $1 \mathrm{~mm}$. The polymer or physical mixture was added to the bottom plate and preheated to the set temperature for 5 minutes. The separation distance between the plates was then reduced to $1 \mathrm{~mm}$. Time-dependent stability of melts was measured by maintaining a constant oscillation frequency and strain over a fixed period of time. This test was performed at temperatures of 100,110 and $130^{\circ} \mathrm{C}$, at a strain of $1 \%$ and a frequency of $10 \mathrm{~Hz}$ for 30 minutes, whilst complex viscosity was measured every 5 seconds.

\subsection{Extrusion of artemisinin and Soluplus ${ }^{\circledR}$}


Extrusion was carried out using a co-rotating twin screw extruder (Pharmalab, Thermo Scientific, UK) with a screw root diameter of $16 \mathrm{~mm}$ and a maximum screw length to diameter ratio of 40:1. Two extruder temperature profiles were applied (T110A and T110B as detailed in Table 1) at a constant screw rotation speed of $50 \mathrm{rpm}$. Residence time (i.e. the amount of time the extruded material spends at temperature inside the process) has a significant impact on the quality of the extruded material. Here two different screw lengths were employed to study the effect of residence time; the longer extruder screws corresponding to higher residence time. Half and full screw lengths were employed, as described in Table 2. Powdered blends of artemisinin and polymer were fed into the extruder at a rate of $120 \mathrm{~g} / \mathrm{h}$ using a gravimetric twin screw feeder (Brabender, Germany). Each batch was of 50g. Extruded formulations were labelled ArtSD1, ArtSD2 and ArtSD3 (detailed formulation codes with processing parameters are provided in Table 3). Following extrusion, the extruded strand was air cooled and pelletized. The pellets were of $2 \mathrm{~mm}$ diameter and $1 \mathrm{~mm}$ thickness. Extrudates were subsequently milled and analysed through powder X-ray diffraction (PXRD), DSC, invitro dissolution and pharmacokinetic studies.

\subsection{Powder X-ray diffraction}

PXRD patterns were recorded using an X-ray Bruker D8 powder diffractometer with an X-ray wavelength of $0.154 \mathrm{~nm}$, Cu source, $40 \mathrm{keV}$ voltage and a filament emission of $40 \mathrm{~mA}$. Samples were scanned from 2 to $30^{\circ}(2 \theta)$ using a $0.01^{\circ}$ step width and a 1 second time count. The scatter slit was set at $0.2^{\circ}$ and the receiving slit at $1^{\circ}$.

\subsection{Assay}

Solid dispersions equivalent to $20 \mathrm{mg}$ of artemisinin were weighed accurately and dissolved in a suitable quantity of medium containing $10 \%(\mathrm{v} / \mathrm{v})$ ethanolic water and 0.1\% (w/v) sodium lauryl sulphate. An appropriate quantity was alkali treated using 
0.2\% $\mathrm{NaOH}$. Drug content was measured at $290 \mathrm{~nm}$ using a UV spectrophotometer. Analysis of data was performed using PCP-Disso software (Poona College of Pharmacy, V3, Pune, India).

\subsection{In-vitro Dissolution}

In-vitro dissolution studies were performed using a USP-XXVI type 2 paddle test apparatus (Copley Scientific, UK). Pellet samples equivalent to $20 \mathrm{mg}$ of artemisinin were placed in dissolution vessels containing $600 \mathrm{ml}$ of dissolution medium maintained at $37^{\circ} \mathrm{C} \pm 0.1^{\circ} \mathrm{C}$ and stirred at $100 \mathrm{rpm}$. The dissolution medium consisted of ethanol $10 \%$ ethanolic water and sodium lauryl sulphate $(0.1 \% \mathrm{w} / \mathrm{v})$. Samples were collected periodically and replaced with fresh dissolution medium. The collected sample was filtered using a $0.45 \mu \mathrm{m}$ cellulose acetate filter and treated with alkali. The concentration of artemisinin was determined spectrophotometrically at $290 \mathrm{~nm}$. Data was analysed by PCP Disso software V3 (Poona College of Pharmacy, Pune, India).

\subsection{Pharmacokinetic study}

\section{Study protocol}

A study was performed with prior approval from the Institutional Animal Ethical Committee (IAEC) of C U Shah College of Pharmacy, Mumbai, India whose guidelines were followed throughout the studies. 36 healthy albino wistar rats with a weight 180200 gm were divided into three groups; control, pure drug and ArtSD3. A sparse technique was used to collect blood samples $(n=6)$. The animals were housed in standard metabolism cages and fasted for 12 hours before dosing but allowed free movement and access to water throughout the experiment. $100 \mathrm{mg}$ of artemisinin was dispersed in $0.5 \%$ aqueous carboxymethyl cellulose (CMC) solution and the oral dose (equivalent to $100 \mathrm{mg}$ of artemisinin) was administered using an oral syringe. At 
predetermined time intervals, blood samples were obtained by the retro orbital technique and collected in ethylene diamine tetra acetic acid (EDTA) tubes.

\section{Sample analysis}

Plasma was obtained by centrifugation of the blood sample at 3500 rpm for 15 minutes. A volume of $200 \mu \mathrm{l}$ plasma was pipetted into Eppendorf tubes and $100 \mu \mathrm{l}$ of internal standard (artemether solution $1000 \mu \mathrm{l} / \mathrm{ml}$ ) and $700 \mu \mathrm{l}$ methanol were added. The solution was vortexed for 2 minutes and the organic phase separated by centrifugation. The collected sample was then subjected to analysis by HPLC (Agilent Technologies, 1200 series, Wokingham, UK). The plasma level of artemisinin was analysed by HPLC using 65\% acetonitrile and 35\% water as the mobile phase. The HPLC system utilised a UV detector set at $210 \mathrm{~nm}$ and a C18 column (250 x $4.6 \mathrm{~mm})$. Artemisinin exhibits a maximum UV absorption at $210 \mathrm{~nm}$. The limits of detection and quantification were 1.01 and $3.06 \mu \mathrm{g} / \mathrm{ml}$, respectively. The concentration against peak area graph plot was found to be linear $\left(r^{2}=0.998\right)$.

\subsection{Stability}

All extrudates were stored at room temperature in a desiccator at $33 \% \mathrm{RH}$ and their stability was studied at 1 month, 3 months, 6 months, 9 months and 12 months by PXRD and dissolution using the above method. The PXRD patterns of ArtSD3 at 1 month, 3 months, 6 months, 9 months, 12 months and 24 months are shown in figure 10 . There was no variation in the result due to time, which proves that the stability of the HME prepared artemisinin: Soluplus ${ }^{\circledR}$ solid dispersions.

\section{Results and Discussion}

Prior to extrusion, all API-polymer mixtures were studied using thermal and rheological analysis. These results are described initially, prior to extrusion results and characterisation of the extruded formulations being presented. 


\section{Thermal analysis}

HME is performed at an elevated temperature and therefore it is necessary to determine the onset of degradation of the API and polymer. Thermo-gravimetric analysis (TGA) was carried out to determine the onset of degradation of pure artemisinin and Soluplus ${ }^{\circledR}$ (Fig. 2). Results showed the onset of degradation of pure artemisinin at $160^{\circ} \mathrm{C}$ and rapid weight loss from $170^{\circ} \mathrm{C}$. This degradation was found to result in a mass loss of $15.73 \%$ between $170^{\circ} \mathrm{C}$ and $200^{\circ} \mathrm{C}$ whereas Soluplus ${ }^{\circledR}$ demonstrated good thermal stability up to $200^{\circ} \mathrm{C}$. Soluplus ${ }^{\circledR}$ showed the presence of moisture at a level of $2-5 \%(\mathrm{w} / \mathrm{w})$, evidenced by a mass loss up to a temperature of $100^{\circ} \mathrm{C}$.

\section{Rheological Characterisation}

API and polymer interaction was evaluated using oscillatory rheometry. Samples may undergo structural changes such as plasticisation, cross linking and change in scissor or degradation when subjected to high temperature and shear for extended periods of time; time dependent data obtained by oscillatory rheometry can be similar to typical HME residence times. Ideally, the viscosity of the polymer should remain constant at a given temperature; changes in viscosity may indicate structural changes in the material. From the TGA results discussed above, temperatures of 110 and $130^{\circ} \mathrm{C}$ were selected for rheological characterisation. The complex viscosities of the polymer with different drug loadings subjected to constant oscillatory shear at $110^{\circ} \mathrm{C}$ and $130^{\circ} \mathrm{C}$ are shown in Fig.3. For pure Soluplus ${ }^{\circledR}$, the viscosity remained stable for 20 minutes at $110^{\circ} \mathrm{C}$ and $130^{\circ} \mathrm{C}$. The plasticising effect of artemisinin can be clearly observed as a reduction in complex viscosity with increasing drug loading; a colour change of the material from white to brown was also observed, suggesting that degradation had occurred during the test. No discolouration was observed when Soluplus ${ }^{\circledR}$ and artemisinin were separately subjected to oscillatory rheometry at the highest set temperature of $130^{\circ} \mathrm{C}$, indicating an 
interaction between the two materials lead to the observed degradation. Colour changes in samples tested at $110^{\circ} \mathrm{C}$ were less intense than samples processed at $130^{\circ} \mathrm{C}$ and the level of applied shear did not significantly affect the colour or colour intensity of the samples. The colour change was found to occur after approximately 10 minutes of shear application, indicating a time and temperature dependent interaction.

It is reported that although artemisinin itself is acidic in nature, it contains a sesquiterpene lactone ring with an unusual peroxide bridge ${ }^{22}$. This lactone ring undergoes electrochemical reduction at a basic $\mathrm{pH}$. To determine whether the moisture present in the polymer produced a basic $\mathrm{pH}$ microenvironment which influenced degradation, $\mathrm{pH}$ of the pure Soluplus ${ }^{\circledR}$ slurry was measured and found to be 7.5. Soluplus ${ }^{\circledR}$ contains $2-5 \%$ (w/w) moisture which was suspected to cause the alkaline microenvironment which promoted artemisinin degradation. In an attempt to counteract this degradation, small amounts of citric acid were added to the drug and polymer mixture to reduce the $\mathrm{pH}$ and the number of heavy metal ions potentially responsible for the discolouration. In addition to prevention of degradation, $\mathrm{pH}$ modifier can increase the dissolution profile, reduce the crystallinity of API and inhibit the recrystallization of a solid dispersion system ${ }^{23}$. Yang et al reported that the selection of the acid was important for controling the $\mathrm{pH}$ of a system and the interactions in the final solid dispersion ${ }^{24}$. Rheological characterisations were carried out with the addition of 2 and $5 \%(\mathrm{w} / \mathrm{w})$ citric acid to the $50 \%$ artemisinin physical mixture. No discolouration of the samples containing 5\% citric acid was observed but some discolouration was present with $2 \%(\mathrm{w} / \mathrm{w})$ citric acid. This indicates that citric acid suppressed degradation by avoiding the exposure of artemisinin to an alkaline microenvironment. When the physical mixture $(1: 1)$, containing $5 \%$ citric acid, was processed at $110^{\circ} \mathrm{C}$, there was a slight decrease in the complex viscosity for the initial 3 minutes, followed by the 
viscosity remaining relatively constant (as shown in Fig.2). It was therefore decided to investigate formulations with and without addition of citric acid in HME.

\section{Extrusion}

From the results of thermal and rheological characterisations, formulations were processed using $\mathrm{HME}$ at a set temperature of $110^{\circ} \mathrm{C}$ with a $50 \%$ artemisinin loading. Artemisinin and polymer were extruded, together with a separate batch containing $50 \%$ drug, $45 \%$ polymer and $5 \%$ citric acid. An extruder temperature profile of $110^{\circ} \mathrm{C}$ was used, being found to generate moderate levels of torque on the extruder screws and to provide a suitable extrudate consistency. Due to the thermally sensitive nature of the material, full and half-length screws were used to vary the residence time of the material at temperature. Three formulations were extruded for further analysis: ArtSD1, ArtSD2 and ArtSD3. ArtSD1 was produced using the half length extruder screw configuration whereas ArtSD2 (without citric acid) and ArtSD3 (with citric acid) were produced using a full length extruder screw configurations. Full details of temperature profiles, screw configurations and formulations are summarised in Tables 1, 2 and 3 respectively.

\section{Assay}

Artemisinin does not contain a chromophore and hence it was difficult to find a sensitive and appropriate analytical method. A UV method was selected which involved post derivatisation. This was based on the formation of an alkali salt of artemisinin (Q292) formed by treatment with $0.2 \% \mathrm{NaOH}$ at $40^{\circ} \mathrm{C}$, however the product was not coloured $^{25}$. From visual observation of the extrudates, ArtSD2 was darker in colour compared to ArtSD1. This degradation was mirrored in the assays; $83.30 \%$ and $78.65 \%$ for ArtSD1 and ArtSD2 respectively. However, the modified formulation ArtSD3 (containing citric acid) was found to be 99.76\%. As ArtSD3 yielded the highest drug 
content, this formulation was used for further characterisation. All assay results are presented in Table 4.

\section{Thermal analysis}

DSC thermograms of artemisinin, Soluplus ${ }^{\circledR}$ and their physical mixture are shown in Fig. 4. Artemisinin exhibited two melting endotherms a major endotherm at $154.81^{\circ} \mathrm{C}$ and an exotherm at $180^{\circ} \mathrm{C}$, representing the liberation of formic acid, the same exotherm was also observed in the physical mixture but commenced at a lower temperature. Soluplus ${ }^{\circledR}$ exhibited a Tg at $70^{\circ} \mathrm{C}$ whereas the physical mixture exhibited Tg at $80^{\circ} \mathrm{C}$ and a sharp endotherm at $154.75^{\circ} \mathrm{C}$.

The DSC thermograms of citric acid, the physical mixture containing 5\% citric acid and ArtSD3 are shown in Fig. 5. Citric acid exhibited a melting endotherm at $156^{\circ} \mathrm{C}$ followed by thermal degradation. The physical mixture containing citric acid exhibited a glass transition temperature at $90^{\circ} \mathrm{C}$. ArtSD3 showed an exotherm at $180^{\circ} \mathrm{C}$, representing the liberation of formic acid; however the material did not exhibit a melting endotherm corresponding to that of artemisinin, indicating that an amorphous state of the solid dispersion had been achieved.

\section{Powder X-ray Diffractometry}

The effect of processing parameters on physical properties was examined by comparing X-ray diffraction patterns of ArtSD3 with artemisinin, Soluplus ${ }^{\circledR}$ and physical mixtures as shown in Fig. 6. Artemisinin exhibited characteristic peaks at $2 \theta$ of $7.5,12,14.5$, 20.2 and 21.9 degrees, while Soluplus ${ }^{\circledR}$, being amorphous in nature, did not show any crystalline peaks. For the physical mixture, crystalline peaks of artemisinin were clearly observed. The complete disappearance of crystalline peaks in ArtSD3 illustrated that the prepared solid dispersion using Soluplus ${ }^{\circledR}$ was transformed into an amorphous state. The intensity of the crystalline peaks was low for the physical mixture when compared 
to those for pure artemisinin. This signifies that the presence of Soluplus ${ }^{\circledR}$ had no influence on the physical state of artemisinin.

\section{In-vitro dissolution study}

The pharmaceutical performance of the extrudates was investigated by in-vitro dissolution and compared with the pure drug and physical mixture, as shown in Fig. 7. The dissolution profile of ArtSD3 was significantly higher compared to that of the pure drug. The dissolution rate of the physical mixture was greater than that of pure artemisinin, although not considerably. In the first 45 minutes, 92\% of the drug was released from ArtSD3 which is presumably due to transferring the crystalline state to the amorphous state resulting in a higher dissolution rate. This compared to release of only $12 \%$ in the same time for pure Artemisinin. In a previous study, $75 \%$ of drug release was achieved in 60 minutes from solid dispersions of artemisinin with PVP (1:5 ratio) prepared by supercritical fluid technology ${ }^{16}$. Therefore, Soluplus ${ }^{\circledR}$ was found to be more effective in improving the dissolution rate of artemisinin. Soluplus ${ }^{\circledR}$ has the ability to solubilise the hydrophobic drug due to its amphiphilic nature through micelle formation $^{26}$. In addition, the incorporation of $\mathrm{pH}$ modifier may have contributed to dissolution enhancement.

Artemisinin is a Biopharmaceutical Classification System (BCS) class II drug meaning that it has low solubility and high permeability. It has been reported that artemisinin has only $8-10 \%$ bioavailability, a short half-life and a high first pass metabolism ${ }^{27}$; these properties contribute to partial parasite removal resulting in artemisinin recrudescences ${ }^{16}$. Jinadasa et al observed that the absorption of artemisinin was negligible when it reached the lower gastrointestinal (GI) tract specifically the colon $^{28}$. Thus, enhancing the solubility of artemisinin could ensure better drug dissolution in the upper GI tract, greater bioavailability and in turn lower chances of recrudescence. A 
rapid dissolution rate and hence absorption could lead to enzyme saturation during the first pass in the liver, resulting in a higher fraction of unmetabolized drug entering the systemic circulation, compared to a slower rate of drug dissolution.

\section{Pharmacokinetic study}

The bioavailability of pure artemisinin and ArtSD3 were studied in albino rats, in order to verify the correlation between in vivo data and data obtained by the in vitro dissolution method. Twelve rats were used for each formulation and samples were analysed once. A plasma concentration against time curve was obtained after oral administration of formulations. The plasma concentrations for pure artemisinin and ArtSD3 are displayed in Table 5 and 6 respectively. Plasma concentration of ArtSD3 clearly shows the enhanced bioavailability of ArtSD3 compared to the pure drug, as shown in Fig. 8. Maximum artemisinin concentration in plasma was reached by ArtSD3 which is approximately five times greater than the pure drug demonstrating significantly improved release in the amorphous state. A typical chromatogram of a rat plasma sample spiked with $120 \mu \mathrm{g} / \mathrm{ml}$ artemisinin RT 9.96 and internal standard artemether RT 16.68 is shown in Fig. 9. The areas under the curves for both pure artemisinin and ArtSD3 are shown in table 7. ArtSD3 showed a three-fold increase in AUC compared to pure artemisinin. The average $\mathrm{C}_{\max }$ concentration (maximum plasma concentration) for artemisinin and the ArtSD3 were $16 \mu \mathrm{g} / \mathrm{ml}$ and $40 \mu \mathrm{g} / \mathrm{ml}$ respectively, whereas $\mathrm{T}_{\max }$ (time to reach $\mathrm{C}_{\max }$ ) was 4 hours for both.

\section{Stability}

Although an interest in solid dispersions is growing rapidly, the commercialisation of solid dispersions in the pharmaceutical industry is limited. The formulation stability is a major issue for solid dispersions owing to phase separation ${ }^{29}$. There are also chances of crystallisation occurring during storage as the drug is molecularly dispersed. The PXRD 
pattern, DSC thermograms and dissolution profiles of the solid dispersion (ArtSD3) were analysed after 1, 3, 6, 9 and 12 months. The amorphous solid dispersion was found to be stable for more than a year without evidence of recrystallization. The improved stability of ArtSD3 during storage is attributed to strong intermolecular interaction between the drug and polymer which reduces the chances of molecular mobility and recrystallization.

\section{Conclusions}

A novel melt extruded formulation of the poorly soluble thermolabile drug artemisinin was developed, using the amphiphilic copolymer Soluplus ${ }^{\circledR}$. The extruded material was completely amorphous in nature and a small amount of citric acid was incorporated to suppress degradation of the drug at extrusion temperatures. Release rates of the drug were significantly improved compared to the pure drug and physical mixture or drug and polymer, in both in vitro and in vivo studies. The system was shown to be stable up to at least 12 months, highlighting the potential for enhancement in delivery of this important but challenging API.

\section{Acknowledgement}

The authors are thankful to BASF for the gift sample of Soluplus ${ }^{\circledR}$. This work was supported by the EPSRC grant no (EP/J003360/1) and UKIERI: UK-India Education and Research Initiative (TPR 26).

\section{References}

1. Leuner C, Dressman J. Improving drug solubility for oral delivery using solid dispersions. Eur J Pharma, Biopharm. 2000; 50: 47-60.

2. Maniruzzaman M, Rana MM, Boateng JS, Mitchell JC, Douroumis D. Dissolution enhancement of poorly water-soluble APIs processed by hot-melt extrusion using hydrophilic polymers. Drug Dev Ind Pharm.2013; 39: 218-227. 
3. Chokshi RJ, Sandhu HK, Iyer RM, Shaw NH, Malick AW, Zia H. Characterization of physico-mechanical properties of indomethacin and polymers to assess their suitability for hot melt extrusion processes as a means to manufacture solid dispersion/solution. J Pharma Sci. 2005; 94: 2463-2474.

4. Thumma S, Sohly MA, Zhang SQ, Gul W, Repka MA. (2005). Influence of plasticizers on the stability and release of a prodrug of $\Delta^{9}$-tetrahydrocannabinol incorporated in poly (ethylene oxide) matrices. Eur J Pharm Biopharm. 2005; 70: 605-614.

5. Karandikar H, Ambardekar R, Kelly A, Gough T, Paradkar A. Systematic identification of thermal degradation products of HPMCP during hot melt extrusion process. Int J Pharm. 2015; 486: 252-258.

6. Liu J, Cao F, Zhang C, Ping Q. Use of polymer combinations in the preparation of solid dispersions of a thermally unstable drug by hot-melt extrusion. Acta Pharmaceutica Sinica. 2013; B3; 263-272.

7. Daly P, Bruce D, Melik D, Harrison G. Thermal degradation kinetics of Poly (3hydroxyhexanoate). J Appl Polym Sci. 2005; 98: 66-74.

8. Follonier N, Doelker E, Cole ET. Evaluation of hot-melt extrusion as a new technique for the production of polymer-based pellets for sustained-release capsules containing high loading of freely soluble drugs. Drug Dev Ind Pharm. 1994; 20: $1323-1339$.

9. Ghebremeskel A, Vemavarapu C, Lodaya M. Use of surfactants as plasticizers in preparing solid dispersions of a poorly soluble APIs. Int J Pharma. 2007; 328: 119129.

10. Repka MA, Majumdar S, Battu SK, Srirangam R, Upadhye SB. Applications of hot-melt extrusion for drug delivery. Expert Opin Drug Dev. 2008; 5: 1357-1376. 
11. Repka MA, Gerding TG, Repka SL, McGinity JW. Influence of plasticizers and drugs on the physical-mechanical properties of hydroxypropylcellulose films prepared by hot melt extrusion. Drug Dev Ind Pharm. 1999; 25: 625-633.

12. Repka MA, Gerding TG, Repka SL, McGinity JW. Influence of plasticizers and drugs on the physical-mechanical properties of hydroxypropylcellulose films prepared by hot melt extrusion. Drug Dev Ind Pharm. 1999; 25: 625-633.

13. WHO, Roll back malaria, World malaria report: section III global financing, commodities and services delivery. 2011

14. Chen J, Gu J, Zhao R, Dai R, Wang J. Simultaneous Nonchiral Determination of Artemisinin and Arteannuin B in Artemisia annua Using Circular Dichroism Detection. Chromatographia, 2008; 69: 361-363.

15. Mooter V, Nijlen TV, Brennan K, Blaton N, Kinget R, Augustijns P. Improvement of the dissolution rate of artemisinin by means of supercritical fluid technology and solid dispersion. Int J Pharm. 2003; 254: 173-181.

16. Titulaer HAC, Zuidema J, Lugt CB. Formulation and pharmacokinetics of artemisinin and its derivatives. Int J Pharm. 1991; 69: 83-92.

17. Kakran M, Sahoo NG, Li L, Judeh Z. Dissolution enhancement of artemisinin with $\beta$-cyclodextrin. Chem Pharm Bull (Tokyo). 2011; 59: 646-52.

18. Zsombor KN, Attila B, Vajna B, Attila F, Patyi G, Kramarics A, Marosi G. Comparison of electrospun and extruded soluplus ${ }^{\circledR}$-based solid dosage forms of improved dissolution. J Pharm Sci. 2012; 101: 322-332.

19. Djuris J, Nikolakakis I, Ibric S, Djuric Z, Kachrimanis K. Preparation of carbamazepine-Soluplus solid dispersions by hot-melt extrusion, and prediction of drug-polymer miscibility by thermodynamic model fitting. Eur J Pharm Biopharm. 2016; 84: 228-237. 
20. Tian Y, Booth J, Meehan E, Jones D, Li S, Andrews GP. Construction of drug-polymer thermodynamic phase diagrams using Flory-Huggins interaction theory: identifying the relevance of temperature and drug weight fraction to phase separation within solid dispersions. Mol Pharma. 2013; 10: 236-248.

21. Lakshman JP, Cao Y, Kowalski J, Serajuddin A, Application of Melt Extrusion in the Development of a Physically and Chemically Stable High-Energy Amorphous Solid Dispersion of a Poorly Water-Soluble Drug. Mol Pharma. 2008; 5: 994-1002.

22. Eckstein-Ludwig U, Webb RJ, Goethem IDA, East JM, Lee AG, Kimura M, Bray PG, Wrad SA, Krishna S. Artemisinins target the SERCA of Plasmodium falciparum. Nature. 2003; 424: 957-961.

23. Tran PH, Tran HT, Lee BJ. Modulation of microenviromental $\mathrm{pH}$ and crystallinity of ionisable telmisartan using alkalizers in solid dispersions for controlled release. $\mathrm{J}$ Control Release. 2008; 129: 59-65.

24. Yang M, He S, Fan Y, Wang Y, Ge Z, Shan L, Gong W, Huang X, Tong Y, Gao C. Microenvironmental pH-modified solid dispersions to enhance the dissolution and bioavailability of poorly water soluble weakly basic GT0918, a developing antiprostate cancer drug: Preparation, characterisation and evaluation in vivo. Int $\mathrm{J}$ Pharm. 2014; 475: 97-109.

25. Wright CW, Artemisia, Taylor and Francis Inc. 2002; 52-53.

26. Yue Z, Guanghui J, Bin T, Hao H, Yuanyuan Z, Jingxin G, Xing T, Haibing H, Yanjiao W. Supersaturation induced by Itraconazole/Soluplus ${ }^{\circledR}$ micelles provided high GI absorption in vivo. Asian J Pharm Sci. 2016; 11: 255-264.

27. Gabor AB. Artemisinin and its derivatives an important new class of antimalarial agents. Pharmacol Therapeut. 2001; 90: 261- 265. 
28. Jinadasa S. Analysis and production of artemisinin, an antimalarial from Artemisia annua L. 1996: University of Science, Malaysia Ph.D Thesis.

29. Ford JL. The current status of solid dispersions. Pharmaceutica Acta Helvae. 1986; 61: 69-88.

\section{Figures}

\section{List of figures:}

Figure 1. Molecular structure of artemisinin

Figure 2. Thermo-gravimetric analysis of artemisinin and Soluplus ${ }^{\circledR}$

Figure 3. DSC thermograms of artemisinin, Soluplus and physical mixture

Figure 4. Time dependent complex viscosity

Figure 5. DSC thermograms of citric acid, physical mixture containing 5\% citric acid and ArtSD3

Figure 6. PXPD patterns of artemisinin, Soluplus ${ }^{\circledR}$, physical mixture and ArtSD3

Figure 7. Drug release rates from pure drug, physical mixture of drug and polymer and ArtSD3

Figure 8. Plasma concentration after oral administrating pure artemisinin and ArtSD3

Figure 9. Typical chromatogram of a rat plasma sample spiked with $120 \mu \mathrm{g} / \mathrm{ml}$ artemisinin RT 9.96 and internal standard artemether RT 16.68<smiles>C[C@H]1CC[C@H]2[C@@H](C)C(=O)O[C@H]3O[C@]4(C)CC[C@@H]1[C@@]23OO4</smiles>

Fig.1. Molecular structure of artemisinin 


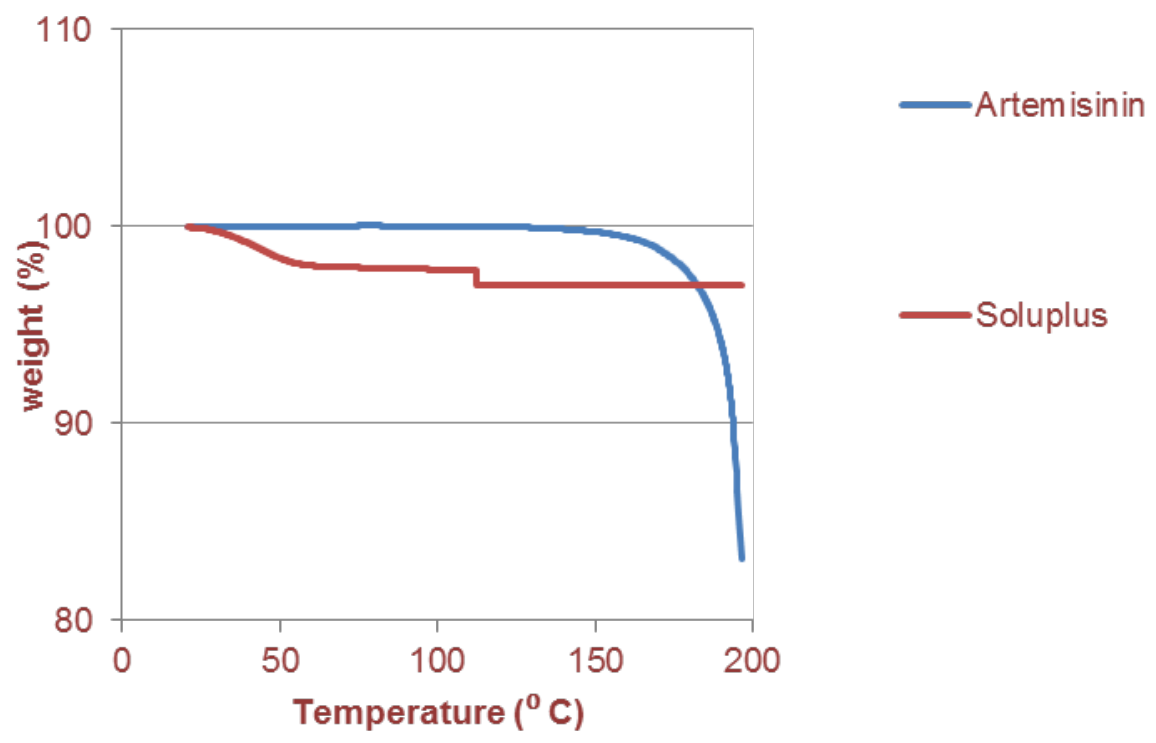

Fig.2. Thermo-gravimetric analysis of artemisinin and Soluplus ${ }^{\circledR}$

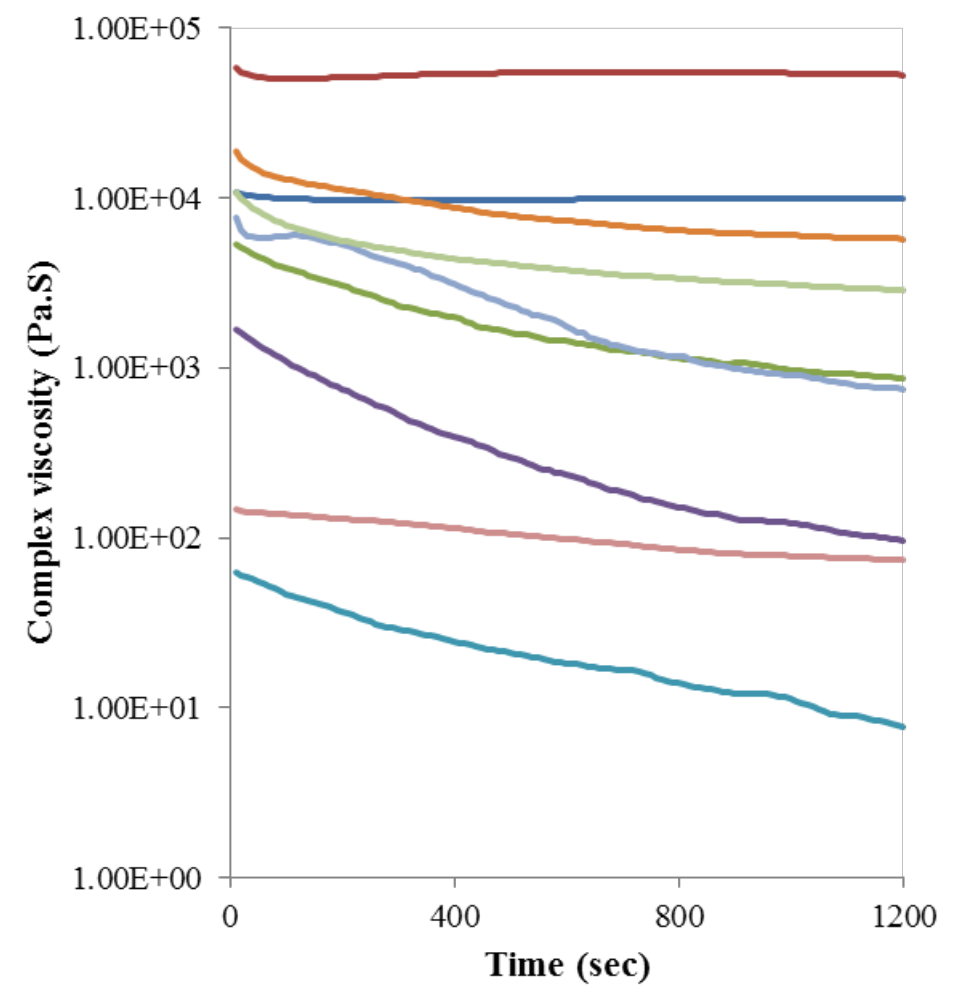

- Soluplus at $130 \mathrm{C}$

Soluplus at $110 \mathrm{C}$

$-20 \%$ art in soluplus at $130 \mathrm{C}$

$-33 \%$ art in soluplus at $130 \mathrm{C}$

$-50 \%$ art in soluplus at $130 \mathrm{C}$

$-20 \%$ art in soluplus at $110 \mathrm{C}$

$-33 \%$ art in soluplus at $110 \mathrm{C}$

$-50 \%$ art in soluplus at $110 \mathrm{C}$

$-50 \%$ art and $5 \%$ citric acid in soluplus at $110 \mathrm{C}^{\prime \prime}$

Fig.3. Time dependent complex viscosity 


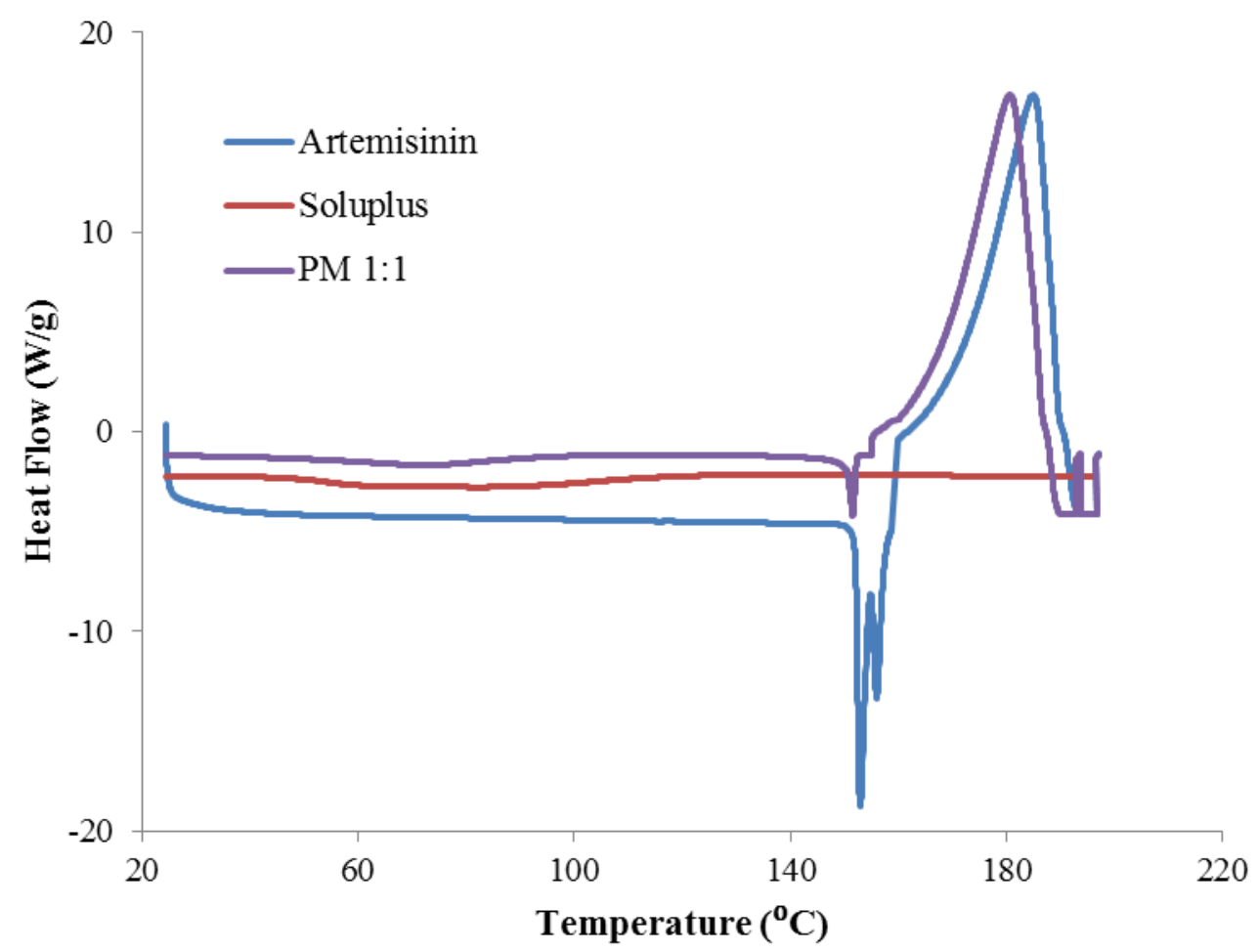

Fig.4. DSC thermograms of artemisinin, Soluplus and physical mixture

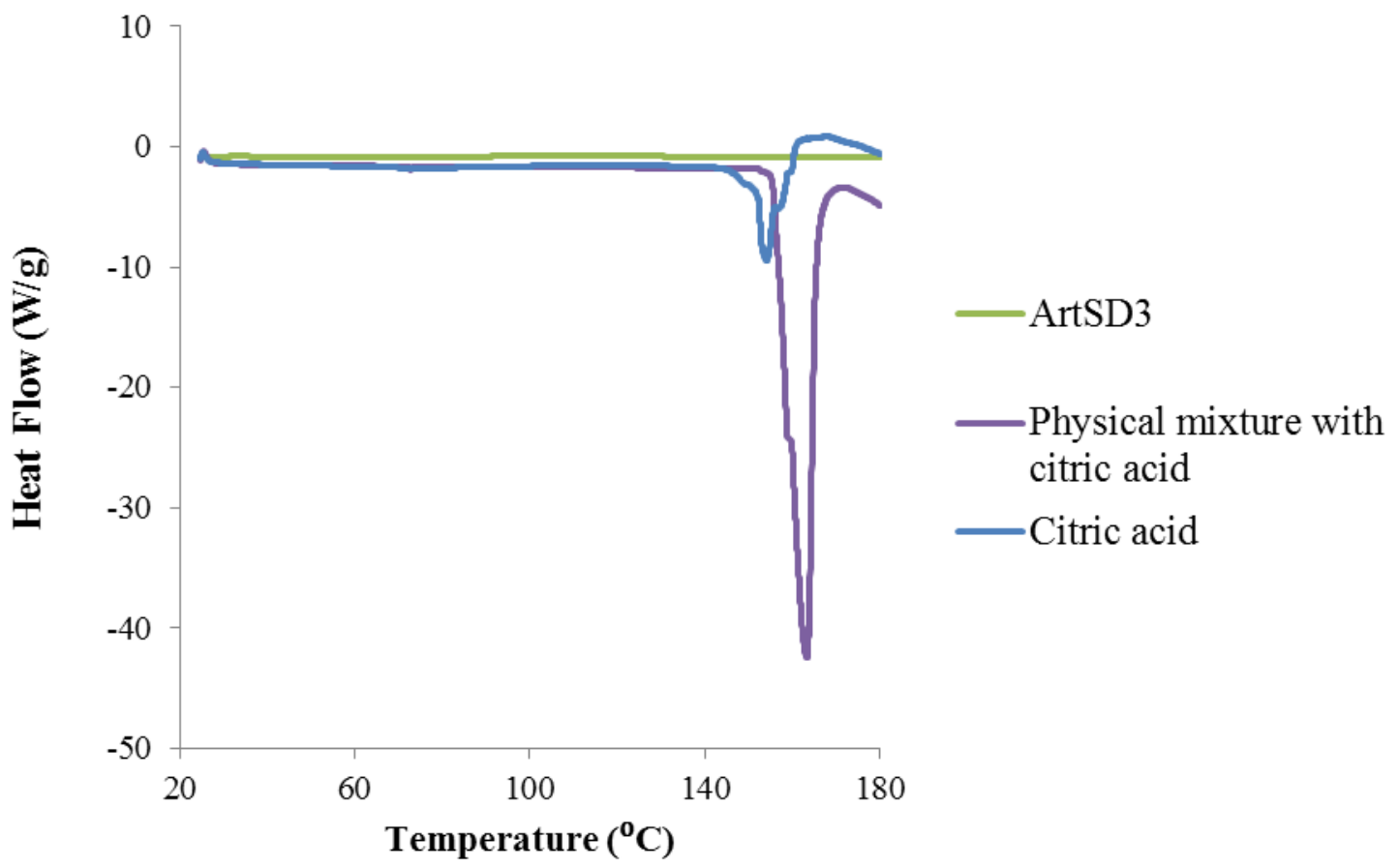

Fig.5. DSC thermograms of citric acid, physical mixture containing $5 \%$ citric acid and ArtSD3 


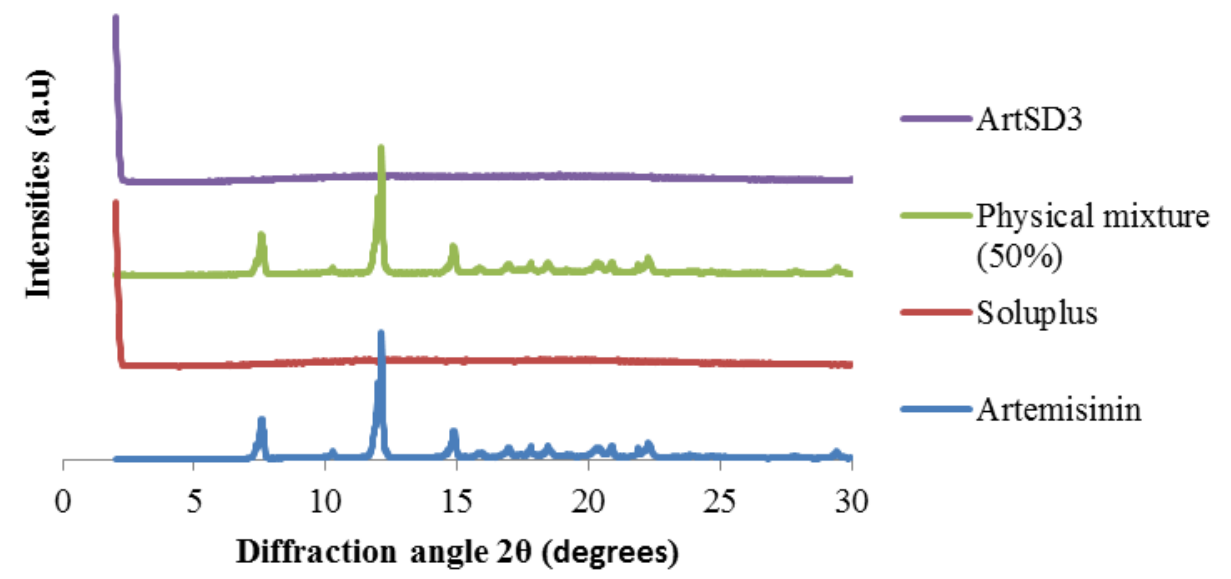

Fig.6. PXPD patterns of artemisinin, Soluplus ${ }^{\circledR}$, physical mixture and ArtSD3

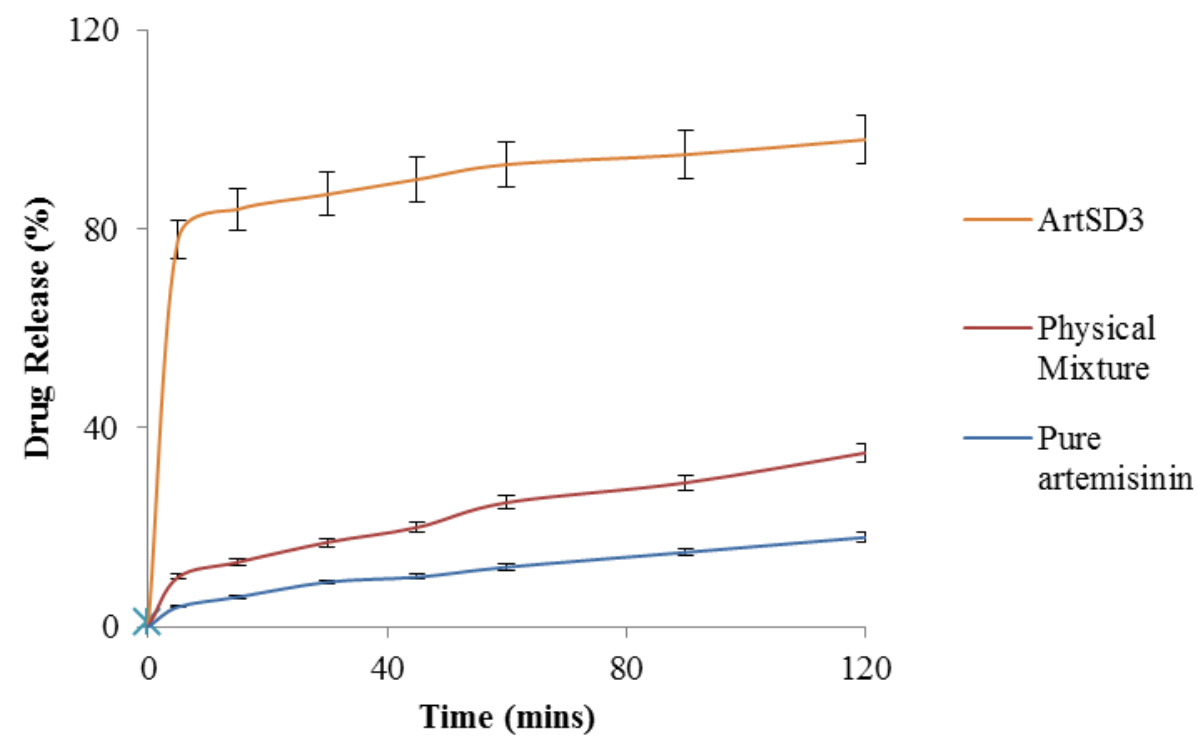

Fig.7. Drug release rates from pure drug, physical mixture of drug and polymer and ArtSD3 


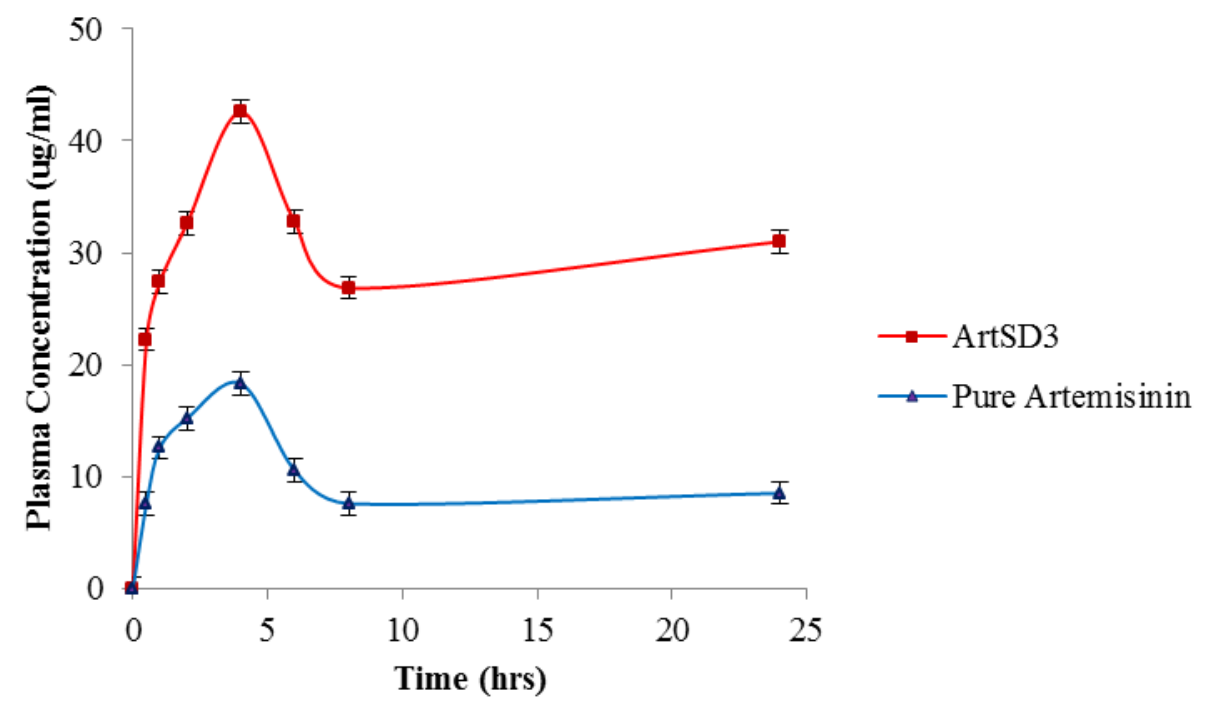

Fig.8. Plasma concentration after oral administrating pure artemisinin and ArtSD3

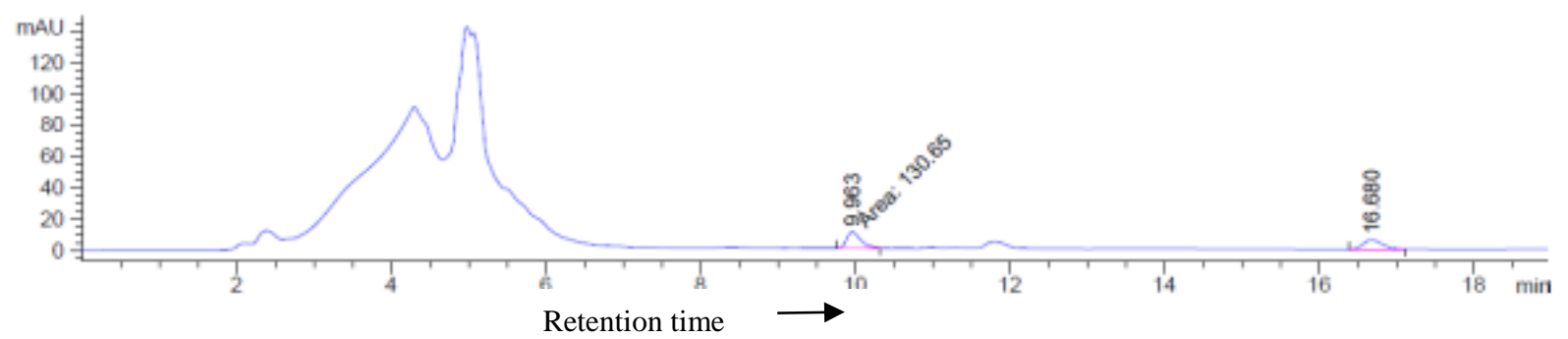

Fig. 9. Typical chromatogram of a rat plasma sample spiked with $120 \mu \mathrm{g} / \mathrm{ml}$ artemisinin RT 9.96 and internal standard artemether RT 16.68

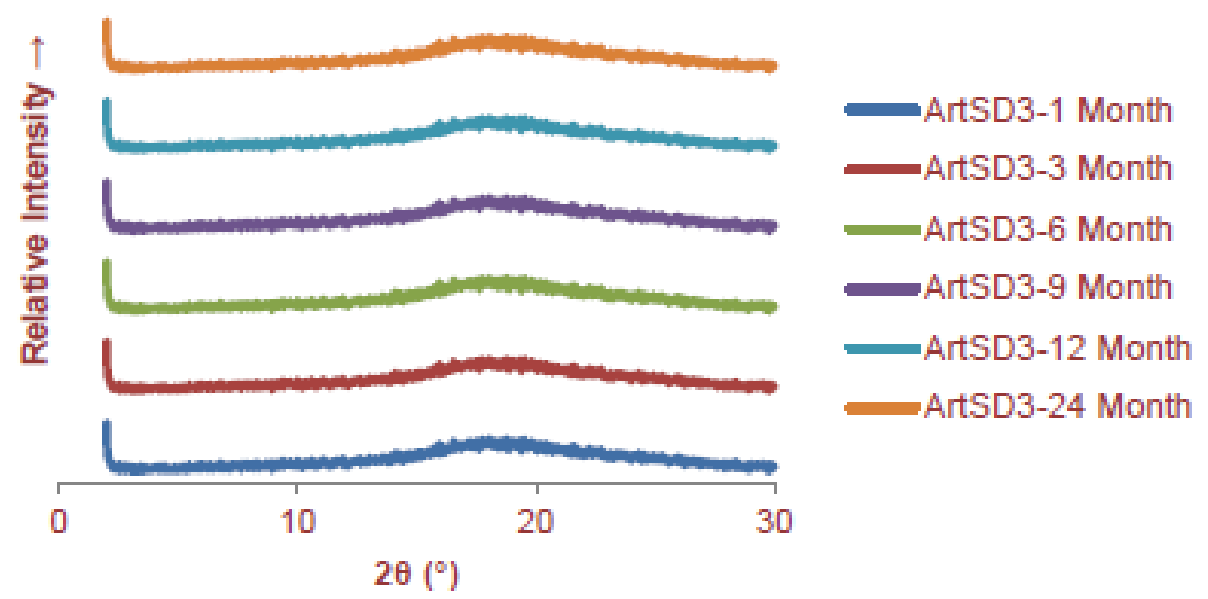

Fig. 10. PXRD patterns of ArtSD3 at different time intervals.

\section{List of tables}




\section{List of tables}

Table 1. Temperature profiles across the different zones of the extruder barrel

Table 2. Screw configurations

Table 3. Formulations codes with process parameters

Table 4. Assay results of extrudates

\section{Tables}

Table 1. Temperature profiles across the different zones of the extruder barrel

\begin{tabular}{|cccccccccc|}
\hline $\begin{array}{c}\text { Temperature } \\
\text { Profile }\end{array}$ & Zone 2 & $\mathbf{3}$ & $\mathbf{4}$ & $\mathbf{5}$ & $\mathbf{6}$ & $\mathbf{7}$ & $\mathbf{8}$ & $\mathbf{9}$ & Die \\
\hline T110 A & - & - & - & - & 25 & 25 & 110 & 110 & 110 \\
\hline T110 B & 20 & 25 & 80 & 90 & 100 & 110 & 110 & 110 & 110 \\
\hline
\end{tabular}

Table 2. Screw configurations

(a: in terms of diameter ID: $16 \mathrm{~mm}$ )

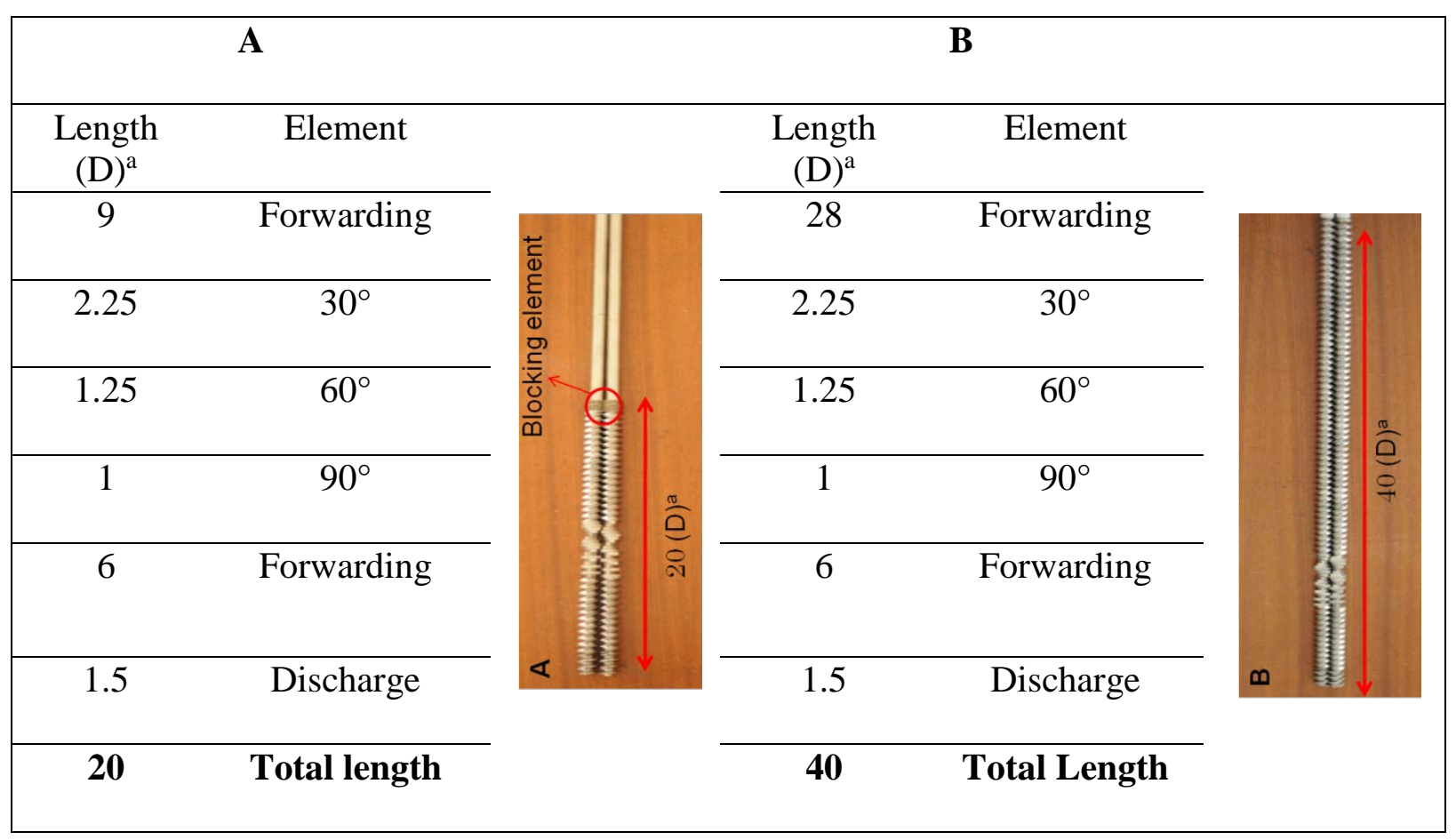

Table 3. Formulations codes with process parameters 


\begin{tabular}{|c|c|c|c|c|c|c|}
\hline \multirow[b]{2}{*}{ Batches } & \multirow{2}{*}{$\begin{array}{c}\text { Screw } \\
\text { configuration } \\
\text { (shown in } \\
\text { Table 3.3) }\end{array}$} & \multicolumn{3}{|c|}{ Proportion } & \multirow{2}{*}{$\begin{array}{l}\text { Temperature } \\
\text { Profiles } \\
\text { (shown in } \\
\text { Table 3.4) }\end{array}$} & \multirow{2}{*}{$\begin{array}{c}\text { Visual } \\
\text { Observation }\end{array}$} \\
\hline & & Drug & & $\begin{array}{l}\text { Citric } \\
\text { acid }\end{array}$ & & \\
\hline ArtSD1 & $\begin{array}{c}\text { A } \\
\text { (Half screw } \\
\text { length) }\end{array}$ & 1 & 1 & - & T110A & \\
\hline ArtSD2 & $\begin{array}{c}\text { B } \\
\text { (Full screw } \\
\text { length) }\end{array}$ & 1 & 1 & - & T110B & \\
\hline ArtSD3 & $\begin{array}{c}\text { B } \\
\text { (Full screw } \\
\text { length) }\end{array}$ & 1 & 0.95 & 0.05 & $\mathrm{~T} 110$ & 2 \\
\hline
\end{tabular}

Table 4. Assay results of extrudates

\begin{tabular}{|l|l|l|}
\hline Formulations & Average Purity (\%) & Standard deviation \\
\hline ArtSD1 & 83.30 & 1.85 \\
\hline ArtSD2 & 78.65 & 2.79 \\
\hline ArtSD3 & 99.76 & 3.54 \\
\hline $\begin{array}{l}\text { Extruded artemisinin } \\
\text { crystals (neat) }\end{array}$ & 99.33 & 0.57 \\
\hline $\begin{array}{l}\text { Extruded Soluplus }{ }^{\circledR} \\
\text { (neat) }\end{array}$ & - & - \\
\hline
\end{tabular}


Table 5. Plasma concentration of pure artemisinin

\begin{tabular}{|llllllll|}
\hline \multicolumn{7}{|c|}{ Plasma Concentration of pure artemisinin $(\boldsymbol{\mu g} / \mathbf{m l})$} \\
\hline Time(h) & Rat 1 & Rat 2 & Rat 3 & Rat 4 & Rat 5 & Rat 6 & Mean \\
\hline $\mathbf{0}$ & 0 & 0 & 0 & 0 & 0 & 0 & 0 \\
\hline $\mathbf{0 . 5}$ & 7.78 & 6.67 & 7.78 & 7.78 & 8.89 & 6.67 & 7.59 \\
\hline $\mathbf{1}$ & 15.56 & 8.89 & 10 & 11.11 & 12.22 & 17.78 & 12.59 \\
\hline $\mathbf{2}$ & 31.11 & 8.89 & 10 & 11.11 & 12.22 & 17.78 & 15.18 \\
\hline $\mathbf{4}$ & 18.89 & 17.78 & 20 & 18.89 & 17.78 & 16.67 & 18.33 \\
\hline $\mathbf{6}$ & 16.67 & 12.22 & 10 & 8.89 & 7.78 & 7.78 & 10.55 \\
\hline $\mathbf{8}$ & 10 & 7.78 & 7.78 & 6.67 & 6.67 & 6.67 & 7.59 \\
\hline $\mathbf{2 4}$ & 8.89 & 10 & 8.89 & 6.67 & 7.78 & 8.89 & 8.51 \\
\hline
\end{tabular}

Table 6. Plasma concentration of ArtSD3

\begin{tabular}{|llllllll|}
\hline \multicolumn{7}{|c|}{ Plasma Concentration of ArtSD3 $(\boldsymbol{\mu g} / \mathrm{ml})$} \\
\hline Time(h) & Rat 1 & Rat 2 & Rat 3 & Rat 4 & Rat 5 & Rat 6 & Mean \\
\hline $\mathbf{0}$ & 0 & 0 & 0 & 0 & 0 & 0 & 0 \\
\hline $\mathbf{0 . 5}$ & 22.22 & 24.44 & 21.11 & 22.22 & 23.33 & 20.00 & 22.22 \\
\hline $\mathbf{1}$ & 27.78 & 26.67 & 26.67 & 26.67 & 28.89 & 27.78 & 27.41 \\
\hline $\mathbf{2}$ & 33.33 & 31.11 & 28.89 & 34.44 & 32.22 & 35.56 & 32.59 \\
\hline $\mathbf{4}$ & 43.33 & 41.11 & 45.56 & 41.11 & 42.22 & 42.22 & 42.59 \\
\hline $\mathbf{6}$ & 26.67 & 33.33 & 35.56 & 32.22 & 33.33 & 35.56 & 32.78 \\
\hline $\mathbf{8}$ & 20.00 & 23.33 & 28.89 & 27.78 & 30.00 & 31.11 & 26.85 \\
\hline $\mathbf{2 4}$ & 13.33 & 18.89 & 20.00 & 18.89 & 20.00 & 17.78 & 18.15 \\
\hline
\end{tabular}

Table 7. Area under curves for pure artemisinin and ArtSD3

\begin{tabular}{|ccc|}
\hline Rats & $\begin{array}{c}\text { Pure artemisinin } \\
\text { ( } \mu \mathrm{g} . \mathrm{hr} / \mathrm{ml})\end{array}$ & $\begin{array}{c}\text { ArtSD3 } \\
(\mu \mathrm{g} . \mathrm{hr} / \mathrm{ml})\end{array}$ \\
\hline Rat 1 & 47.01 & 127.15 \\
\hline Rat 2 & 58.33 & 147.22 \\
\hline Rat 3 & 37.77 & 164.03 \\
\hline Rat 4 & 32.56 & 157.64 \\
\hline Rat 5 & 34.65 & 165.49 \\
\hline Rat 6 & 55.83 & 165.49 \\
\hline
\end{tabular}


